\title{
Tracheostomy in Pediatric Intensive Care Unit: Experience from Eastern India
}

\author{
Mukesh Kumar Jain ${ }^{1}$ (1) $\cdot$ Sibabratta Patnaik ${ }^{1} \cdot$ Bandya Sahoo $^{1} \cdot$ Reshmi Mishra ${ }^{1} \cdot$ Jyoti Ranjan Behera ${ }^{1}$
}

Received: 22 April 2020 / Accepted: 24 September 2020 / Published online: 14 October 2020

(C) Dr. K C Chaudhuri Foundation 2020

\begin{abstract}
Objective Tracheostomy is one of the most commonly used surgical intervention in sick children in the intensive care unit. The literature in the pediatric population is limited, therefore, we conducted this study to evaluate the indications, timing, complications, and outcomes of tracheostomy among the children at our center.

Methods This retrospective study was conducted from January 2016 through December 2019. Data was collected from the patients' records and analyzed.

Results During this study period, 283 children were ventilated, of which $26(9.1 \%)$ required tracheostomy. Among this $73 \%$ were boys. The median age of the children who underwent tracheostomy was $6.32 \mathrm{y}$. The most common indication for tracheostomy was prolonged mechanical ventilation [24 cases $(92 \%)$ ] followed by upper airway obstruction [ 2 cases ( $8 \%)$ ]. The average time of tracheostomy was $11.65 \mathrm{~d}$, range (1-21 d). Complications were seen in 14 patients $(55 \%)$. The most common complications were accidental decannulation, occlusion, pneumothorax, and granulation tissue. Twenty one (80\%) patients were successfully discharged, out of which $16(61 \%)$ patients were discharged after decannulation and $5(21 \%)$ were sent home with a tracheostomy tube in situ. Overall mortality in present study was $11.5 \%$; none was directly related to tracheostomy.

Conclusions The indication for tracheostomy has been changed from emergency to more elective one. Prolonged mechanical ventilation is the most common indication for tracheostomy. Although the timing of tracheostomy is not fixed, two weeks time is reasonable and it can be done safely at the bedside in pediatric intensive care.
\end{abstract}

Keywords Children $\cdot$ Intensive care unit $\cdot$ Indication $\cdot$ Mechanical ventilation $\cdot$ Tracheostomy

\section{Introduction}

Tracheostomy is one of the most commonly used surgical intervention in critically sick children in the intensive care unit. Children need a tracheotomy for various reasons, either as an emergency or an elective procedure. Pediatric tracheostomy is more challenging because of the small, pliable trachea, limited extension of the surgical field and the risk of anesthesia. The morbidity and mortality for Pediatric tracheostomy are around two to three times more than for adult patients [1-4].

The indication for tracheostomy has been significantly changed over the last few decades from upper airway obstructions following infections to prolonged mechanical ventilation

Mukesh Kumar Jain

mukesh26.jain@gmail.com

1 Department of Pediatrics, Kalinga Institute of Medical Sciences, KIIT University, Bhubaneswar, Odisha 751024, India
[5]. With the advent of vaccination against Haemophilus influenza type B and Corynebacterium diphtheria and improvement in the pediatric intensive care, the number of tracheostomies for upper airway disease has been reduced [1]. Now-a-days Pediatric tracheostomy is commonly done for prolonged ventilation, upper airway obstruction, trauma and neurological diseases [6]. In contrary to adults, there is no consensus guideline for the timing of tracheostomy in children [7].

The literature in the pediatric population is limited. Therefore, this study was conducted to analyze the indications, complications and outcomes of tracheostomy at a tertiary care pediatric intensive care unit in Eastern India.

\section{Material and Methods}

This retrospective study was conducted from January 2016 through December 2019. A total of 26 tracheostomies were performed during this period. Data regarding demography, 
indication, timing, complications, and the outcome of tracheostomy was collected and analyzed. After discharge, the patients were followed up at the hospital every 2 mo for at least 6 mo.

All the tracheostomies were carried out by otolaryngologists in the presence of an anesthetist and a pediatric intensivist either in the pediatric intensive care unit (PICU) or in the operation theatre. A standard procedure for tracheostomy was used in all cases. The indication and timing of tracheostomy were decided by the pediatric intensivist. The decannulation protocol of authors' institution includes cannula downsizing and then its gradual occlusion. The decision for the decannulation was combinedly taken but mainly by the treating physicians. Once the child is hemodynamically stable, on minimal or no oxygen, off inotropes then authors planned for the decannulation. A laryngoscopy is performed only when there was difficulty in the decannulation process. The frequency of downsizing depends on the age of the patient and type of tracheostomy tube used initially.

Parents and caregivers were involved in the care of the tracheostomy patient. They were taught about the routine care of the tracheostomy, including suctioning and changing of tubes by demonstration. They were also educated about various equipments like suction catheter, suction machine, pressure set up before discharge etc.

\section{Results}

During the study period, 283 children were ventilated, out of which $26(9.1 \%)$ required a tracheostomy. Among this $73 \%$ were boys. The median age of the children who underwent tracheostomy was $6.32 \mathrm{y}$. The youngest child was 4-mo-old and the eldest was $16 \mathrm{y}$. Seven children were $\leq 1$ y. In 19 (73\%) patients tracheostomy was performed at the bedside in the pediatric intensive care unit.

The most common indication for tracheostomy in present study was prolonged mechanical ventilation secondary to neuromuscular problems - 24 cases $(92 \%)$ followed by upper airway obstruction (UAO) -2 cases $(8 \%)$. The prolonged mechanical ventilation group was further divided into four subgroups as neuromuscular ( 7 children), neurological (10 children), traumatic brain injury due to road traffic accidents ( 5 children) and respiratory ( 2 children) (Table 1$)$.

The average timing of tracheostomy was $11.65 \mathrm{~d}$, range (1-21 d). In 18 (70\%) children it was done within 2 wk and only in $8(30 \%)$ cases after 2 wk. In authors' experience, this delay was because of parental anxiety, stress, and fear about the care of tracheostomy. In 2 cases of upper airway obstruction (UAO), an emergency tracheostomy was performed in the operation theatre.
Emergency tracheostomy was performed in one child in the pediatric intensive care unit due to severe respiratory distress after decannulation (Table 1).

Complications from tracheostomy were seen in 14 patients $(55 \%)$. Out of 14,2 patients had accidental decannulation, 2 had tube occlusion, 1 patient had a cardiac arrest, 2 patients developed pneumothorax, 3 developed granulation tissue, 1 patient had maggots and infection at home, another patient died at home due to occlusion and 1 patient each developed stromal site infection and subglottic stenosis.

Twenty one $(80 \%)$ patients were successfully discharged, of which $16(61 \%)$ patients were discharged after decannulation and $5(21 \%)$ were sent home with a tracheostomy tube in situ. Out of those 5, 2 patients were decannulated on follow-up, 1 child died due to tube occlusion at home, 2 are remaining on tracheostomy for more than $1 \mathrm{y}$. Three patients got discharged against medical advice, out of which one died on the way home, one died at home after 2 wk due to tube occlusion and one patient was lost to follow-up. Overall mortality in present study was $11.5 \%$ (Fig. 1 and Table 1).

\section{Discussion}

Now-a-days tracheostomy is one of the most commonly performed surgical procedures in the pediatric intensive care unit. Over the last $50 \mathrm{y}$, the indication for tracheostomy has been changed from acute inflammatory airway obstructions to prolonged mechanical ventilation. This change is because of the introduction of new vaccines and improvement in neonatal and pediatric intensive care $[1,5]$.

In the present study, the rate of tracheostomy was $9.1 \%$, which is almost similar to a study by Kamit Can et al. [8]. The tracheostomy rate of units varies from 2 to $7 \%$, but the rate with different co-morbidities is not clear [9-11]. The most common indication for tracheostomy in present study was prolonged mechanical ventilation $(92 \%)$ followed by UAO (8\%), which is similar to many recent studies [8-11]. Douglas et al. reported 111 children who underwent tracheostomy and found that the most common indication was prolonged mechanical ventilation $(32 \%)$ followed by craniofacial anomaly causing UAO (18\%) and subglottic stenosis (14\%) [12]. Contrary to present study, Schweiger et al. found that the most common indication for tracheostomy is upper airway obstruction [13]. Mahadevan et al. from New Zealand also reported that $\mathrm{UAO}$ accounts for the majority of tracheostomies [14].

The average timing of the tracheostomy in present study was $11.65 \mathrm{~d}$, range $(1-21 \mathrm{~d})$. As per the unit's protocol, any child who required ventilation for $>1 \mathrm{wk}$, was evaluated for tracheostomy. In the United States, studies have demonstrated that the time for insertion 
Table 1 Demographic characteristics, indications, timings and outcomes of patients with tracheostomy

\begin{tabular}{|c|c|c|c|c|c|c|}
\hline Subgroup & Serial no. & $\begin{array}{l}\text { Age/ } \\
\text { Sex }\end{array}$ & Indication & Timing of tracheostomy & $\begin{array}{l}\text { Duration of } \\
\text { tracheostomy }\end{array}$ & Outcome \\
\hline \multirow[t]{7}{*}{ 1. Neuromuscular (7) } & 1 & $5 \mathrm{y} / \mathrm{F}$ & GBS & $10 \mathrm{~d}$ & $16 \mathrm{~d}$ & Discharged \\
\hline & 2 & $4 \mathrm{mo} / \mathrm{M}$ & $\mathrm{CM}$ & $21 \mathrm{~d}$ & $>100 \mathrm{~d}$ & LAMA, Died \\
\hline & 3 & $4 \mathrm{y} / \mathrm{M}$ & GBS & $7 d$ & $65 \mathrm{~d}$ & Discharged \\
\hline & 4 & $7 \mathrm{y} / \mathrm{M}$ & GBS & $10 \mathrm{~d}$ & $48 \mathrm{~d}$ & Discharged \\
\hline & 5 & $12 \mathrm{y} / \mathrm{F}$ & GBS & $9 \mathrm{~d}$ & $85 \mathrm{~d}$ & Discharged \\
\hline & 6 & $12 \mathrm{y} / \mathrm{M}$ & GBS & $5 \mathrm{~d}$ & Not yet closed & Discharged $^{\mathrm{a}}$ \\
\hline & 7 & $7 \mathrm{y} / \mathrm{F}$ & GBS & $15 \mathrm{~d}$ & $40 \mathrm{~d}$ & Discharged \\
\hline \multirow[t]{10}{*}{ 2. Neurological (10) } & 1 & $9 \mathrm{y} / \mathrm{M}$ & $\mathrm{CP} /$ Seizure & $15 \mathrm{~d}$ & In situ & Discharged $^{\mathrm{b}}$ \\
\hline & 2 & $1 \mathrm{y} / \mathrm{M}$ & Encephalitis & $20 \mathrm{~d}$ & $17 \mathrm{~d}$ & Discharged \\
\hline & 3 & $9 \mathrm{y} / \mathrm{M}$ & AIE & $18 \mathrm{~d}$ & $34 \mathrm{~d}$ & Discharged \\
\hline & 4 & $1 \mathrm{y} / \mathrm{M}$ & Encephalitis & $20 \mathrm{~d}$ & $75 \mathrm{~d}$ & Discharged \\
\hline & 5 & $1 \mathrm{y} / \mathrm{M}$ & JE & $13 \mathrm{~d}$ & $15 \mathrm{~d}$ & Discharged \\
\hline & 6 & $3 \mathrm{y} / \mathrm{M}$ & AIE & $14 \mathrm{~d}$ & $35 \mathrm{~d}$ & Discharged \\
\hline & 7 & $2 \mathrm{y} / \mathrm{M}$ & JE & $10 \mathrm{~d}$ & $65 \mathrm{~d}$ & Discharged \\
\hline & 8 & $1 \mathrm{y} / \mathrm{F}$ & Encephalitis & $10 \mathrm{~d}$ & No data & LAMA \\
\hline & 9 & $7 \mathrm{y} / \mathrm{F}$ & AIE & $10 \mathrm{~d}$ & $60 \mathrm{~d}$ & Discharged $^{\mathrm{a}}$ \\
\hline & 10 & $13 \mathrm{y} / \mathrm{M}$ & Encephalitis & $6 \mathrm{~d}$ & $25 \mathrm{~d}$ & Discharged \\
\hline \multirow{5}{*}{ 3. TBI due to road traffic accidents (5) } & 1 & $14 \mathrm{y} / \mathrm{M}$ & RTA /TBI & $12 \mathrm{~d}$ & Not yet closed & Admitted \\
\hline & 2 & $5 \mathrm{y} / \mathrm{M}$ & RTA/SRSE & $20 \mathrm{~d}$ & Not yet closed & Admitted \\
\hline & 3 & $5 \mathrm{y} / \mathrm{F}$ & RTA (DAI) & $17 \mathrm{~d}$ & Not yet closed & Discharged $^{\mathrm{a}}$ \\
\hline & 4 & $7 \mathrm{y} / \mathrm{M}$ & RTA (DAI) & $7 d$ & $6 \mathrm{mo} 5 \mathrm{~d}$ & Discharged $^{\mathrm{a}}$ \\
\hline & 5 & $7 \mathrm{y} / \mathrm{M}$ & RTA (DAI) & $5 \mathrm{~d}$ & $32 \mathrm{~d}$ & Discharged \\
\hline \multirow[t]{4}{*}{ 4. Respiratory (4) } & 1 & $16 \mathrm{y} / \mathrm{M}$ & Sepsis, pneumonia & $7 d$ & $39 d$ & LAMA \\
\hline & 2 & $6 \mathrm{mo} / \mathrm{M}$ & Sepsis, pneumonia & $13 \mathrm{~d}$ & $43 \mathrm{~d}$ & Discharged \\
\hline & 3 & $5 \mathrm{y} / \mathrm{F}$ & $\begin{array}{l}\text { Laryngeal } \\
\text { papilloma }\end{array}$ & Emergency & $60 \mathrm{~d}$ & Discharged \\
\hline & 4 & $1 \mathrm{y} / \mathrm{M}$ & Foreign body & Emergency & $5 \mathrm{~d}$ & Discharged \\
\hline
\end{tabular}

AIE Auto immune encephalitis; $C M$ Compressive myelopathy; $C P$ Cerebral palsy; DAI Diffuse axonal injury; GBS Guillain barre syndrome; JE Japanese encephalitis; LAMA Left against medical advise; RTA Road traffic accidents; SRSE Super refractory status epilepticus; TBI Traumatic brain injury

a discharged with tube in situ

${ }^{\mathrm{b}}$ discharged and died at home

of a tracheostomy tube is on average, $14.4 \mathrm{~d}$, although it varies significantly in units from 4.3 to $30.4 \mathrm{~d}$ [9, 15]. Holloway et al. analyzed 73 subjects with a median of $22 \mathrm{~d}$ of ventilation before tracheostomy, and suggested that prolonged mechanical ventilation is associated with increased ICU morbidities and stay and recommended early tracheostomy within $14 \mathrm{~d}$ [16]. Although there is a consensus that tracheostomy should be performed in 1 or 2 wk of ventilation in adult patients, no established criteria currently exists regarding the time of tracheostomy in children, and timing of tracheostomy should be individualized for each patient [7, 17]. It is known that the pediatric patients tolerate intubation for a longer period than do adults; however, early tracheostomy not only reduces the work of breathing, ventilator- associated complications, sedation requirements, the length of ICU stay and cost but also improves quality care and patient comfort [17].

The complications of tracheostomy were seen in 14 patients (55\%). Pneumothorax and minor bleeding were two important perioperative complications. Early postoperative complications were occlusion of the tube, accidental decannulation whereas subglottic stenosis and granulation tissue were late complications. One child on tracheostomy had blocked tubes at home and died. Mortality was $11.5 \%$; none was because of a tracheostomy. Kamit Can et al. found that the complication rate was $25.3 \%$ in the pediatric intensive care unit and $11.1 \%$ at home; no patients died of tracheostomyrelated complications, which shows that performing a 
Fig. 1 Outcome of tracheostomy. LAMA Left against medical advise

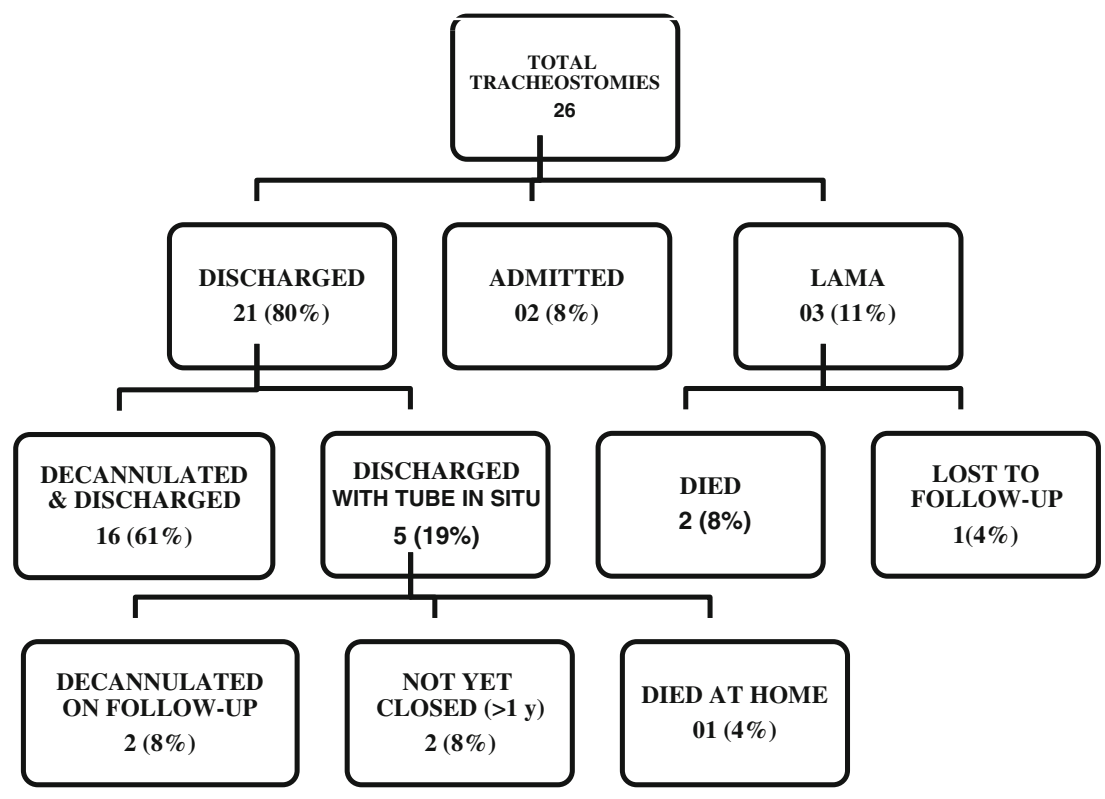

tracheostomy is a relatively safe intervention in the pediatric ICU [8]. The study by Mahadevan et al. found a complication rate of $51 \%$ [14].

The average length of tracheostomy in present study was $48 \mathrm{~d}(5-180 \mathrm{~d})$. In four patients, tracheostomies could not be closed to date: 3 severe traumatic brain injury (TBI) and 1 Guillain barre syndrome (GBS) patients are still on the tube. A study by Schweiger et al. had shown decannulation time ranged from less than one mo to $7 \mathrm{y}$ (median of $5 \mathrm{mo}$ ) [13].

The rate of successful decannulation in present study was $18(69 \%)$ and 2 patients are still waiting for closure and 2 patients need tracheal reconstruction surgery. Studies show that decannulation rates vary around $35-75 \%[1,2,12,14$, 18]. A study by Sharma and Vinayak showed the rate of decannulation was $82 \%$ [19]. The mortality rate of tracheostomy patients is relatively high, between 14 and $19 \%$ [2, 6, $14]$; in the present study, it is $11.5 \%$. Schweiger et al. showed mortality of $32 \%$, which is because of an underlying disease rather than due to tracheotomy [13].

\section{Conclusions}

Tracheostomy is one of the most commonly used procedure now-a-days in the PICU. The indication for tracheostomy has changed from emergency to more of elective one. The most common indication for tracheostomy in present study was prolonged mechanical ventilation. Although the timing of tracheostomy is individualized for each patient, two weeks seems to be reasonable enough. Tracheostomy can be performed safely at the bedside in pediatric intensive care unit, but the patient selection should be made carefully.
Authors' Contributions MKJ, SP and BS: Concept designing, analysis of data, drafting, critical revision and final approval of the manuscript; RM and JRB: Concept designing, analysis of data and final approval of the manuscript. Dr. Natabar Swain, Professor \& HOD, Department of Pediatrics will act as guarantor for this paper.

\section{Compliance with Ethical Standards}

Conflict of Interest None.

\section{References}

1. Özmen S, Özmen Ö, Ünal Ö. Pediatric tracheotomies: a 37-year experience in 282 children. Int J Pediatr Otorhinolaryngol. 2009;73: 959-61.

2. Ang A, Chua D, Pang K, Tan H. Pediatric tracheotomies in an Asian population: the Singapore experience. Otolaryngol Head Neck Surg. 2005;133:246-50.

3. Kremer B, Botos-Kremer A, Eckel H, Schlöndorff G. Indications, complications, and surgical techniques for pediatric tracheostomies - an update. J Pediatr Surg. 2002;37:1556-62.

4. Dal'Astra A, Quirino APL, Quirino AV, Caixêta JA de S, Ameloti M, Avelino G. Tracheostomy in childhood: review of the literature on complications and mortality over the last three decades. Brazilian J Otorhinolaryngol. 2017;83:207-14.

5. Wetmore R, Handler S, Potsic W. Pediatric tracheostomy. Ann Otol Rhinol Laryngol. 1982;91:628-32.

6. Carron J, Derkay C, Strope G, Nosonchuk J, Darrow D. Pediatric tracheotomies: changing indications and outcomes. Laryngoscope. 2000;110:1099-104.

7. Lee $\mathrm{W}$, Koltai $\mathrm{P}$, Harrison A, et al. Indications for tracheotomy in the pediatric intensive care unit population. Arch Otolaryngol Head Neck Surg. 2002;128:1249.

8. Kamit Can F, Anil A, Anil M, et al. The outcomes of children with tracheostomy in a tertiary care pediatric intensive care unit in Turkey. Türk Pediatri Arşivi. 2018;53:177-84.

9. Wood D, McShane P, Davis P. Tracheostomy in children admitted to paediatric intensive care. Arch Dis Child. 2012;97:866-9. 
10. Dursun O, Ozel D. Early and long-term outcome after tracheostomy in children. Pediatr Int. 2011;53:202-6.

11. Da Silva P, Waisberg J, Paulo C, Colugnati F, Martins L. Outcome of patients requiring tracheostomy in a pediatric intensive care unit. Pediatr Int. 2005;47:554-9.

12. Douglas C, Poole-Cowley J, Morrissey S, Kubba H, Clement W, Wynne D. Paediatric tracheostomy - an 11 year experience at a Scottish paediatric tertiary referral centre. Int J Pediatr Otorhinolaryngol. 2015;79:1673-6.

13. Schweiger C, Manica D, Becker C, et al. Tracheostomy in children: a ten-year experience from a tertiary center in southern Brazil. Brazilian J Otorhinolaryngol. 2017;83:627-32.

14. Mahadevan M, Barber C, Salkeld L, Douglas G, Mills N. Pediatric tracheotomy: 17 year review. Int J Pediatr Otorhinolaryngol. 2007;71:1829-35.

15. Wakeham M, Kuhn E, Lee K, McCrory M, Scanlon M. Use of tracheostomy in the PICU among patients requiring prolonged mechanical ventilation. Intens Care Med. 2014;40:863-70.
16. Holloway A, Spaeder M, Basu S. Association of timing of tracheostomy on clinical outcomes in PICU patients. Pediatr Crit Care Med. 2015;16:e52-8.

17. Andriolo BN, Andriolo RB, Saconato H, Atallah ÁN, Valente O. Early versus late tracheostomy for critically ill patients. Cochrane Database Syst Rev. 2015;1:CD007271. https://doi.org/10.1002/ 14651858.CD007271.pub3 (Published 2015 Jan 12).

18. Lawrason A, Kavanagh K. Pediatric tracheotomy: are the indications changing? Int J Pediatr Otorhinolaryngol. 2013;77:922-5.

19. Sharma P, Vinayak N. A single center experience of pediatric tracheostomy. Indian Pediatr. 2018;55:1091-2.

Publisher's Note Springer Nature remains neutral with regard to jurisdictional claims in published maps and institutional affiliations. 